\title{
CARTELES DE LIBROS EN ESPAÑA: ORÍGENES BARROCOS (CON UN APUNTE DECIMONÓNICO)
}

\author{
BOOK POSTERS IN SPAIN: BAROQUE ORIGINS \\ (WITH A NINETEENTH-CENTURY NOTE)
}

Pedro Rueda Ramírez

Universitat de Barcelona

\begin{abstract}
This article involves the study of Spanish posters that advertise the sale of publications printed by bookseller-publishers and printers in the modern world. The array of posters identified and preserved is not extensive, due to their ephemeral nature. However, their utilization is confirmed in documentary sources, references to these posters in gazettes, erudite correspondence, or literary testimonies themselves. I will attempt to demonstrate the role of the poster in the diffusion of publicity for these editorial novelties by considering walls as a space for public communication, serving the purpose of promoting new publications. In this study I consider the Baroque antecedents of the poster and concentrate on examples preserved from the eighteenth century as well as the graphic testimonies of their use, in this case by means of testimonies from the nineteenth century.
\end{abstract}

KEYWORDS: Posters; Edition; Ephemeral Publications; Editorial Novelties; Book Advertising.

RESUMEN: El trabajo se ocupa del estudio de los carteles españoles que anuncian publicaciones a la venta de libreros-editores e impresores en el mundo moderno. El ramillete de carteles identificados y conservados es corto, dado su carácter efímero. Aunque su uso está atestiguado en las fuentes documentales, las referencias en las gacetas a estos carteles, la correspondencia erudita o los propios testimonios literarios. Intentaremos demostrar el papel del cartel en la difusión de las noticias de las novedades, al considerar los muros un espacio de comunicación pública destinado a promocionar nuevas ediciones. En este trabajo nos ocuparemos de los antecedentes barrocos del cartel y nos centraremos en los ejemplares conservados en los siglos xvIII y los testimonios gráficos de su uso, en este último caso a través de testimonios del siglo XIX

PALABRAS CLAVES: carteles; edición; impresos efímeros; novedades editoriales; Publicidad del libro. 
En el territorio de los impresos efímeros del mundo hispánico las aportaciones de Víctor Infantes fueron magistrales, ofreciendo una rara (y poco frecuente) combinación de erudición, afinado análisis bibliográfico y hallazgos de nuevas piezas, rescatadas de mil fuentes dispersas, que al unirse ofrecían una mirada renovada y fresca. Este fue el caso de los impresos de una sola hoja que resultaban un intrincado problema bibliográfico, y especialmente interesante en el caso que nos ocupa, el análisis de los carteles poéticos (Osuna, Infantes, $2011)$. Los trabajos de Víctor Infantes sobre estos raros materiales nos han servido de guía en una investigación en marcha sobre los carteles de venta de libros en España. ${ }^{1}$ Es conveniente recordar que se trata de materiales que pocas veces se conservan. En numerosas ocasiones las informaciones provienen de fuentes secundarias, como recuerda Mandelbrote al ocuparse del catálogo francés de venta de los libros de Thomas Blaise que, en 1641, establece que se venderán «aux jours, lieu $\&$ heures assignez par les affiches, qui pour cét effet, seront mises és lieux $\delta$ endroits accoustumez" (Mandelbrote, 2000: 58). Un cartel, como en tantos otros casos, perdido dado su corta tirada destinada a fijarse en las paredes en los sitios «acostumbrados».

El creciente peso del material «menor» o efímero en la vida cotidiana resulta de notable interés para recuperar unas vivencias que dejaban rastro en las biografías, e incluso sirvieron para componer el día a día de las relaciones, la convivencia y el trato social, como se aprecia en el trampantojo personal de Francisco Antonio de Lacy. En este caso, una mesa llena de impresos, grabados, dibujos, tarjetas de visita y naipes, dibujados por Jorge Juan Guillelmi en 1783, revelaba intereses artísticos, devociones, documentos de trabajo, dedicatorias impresas o folletos, que todos revueltos dan idea de la vorágine de un diplomático, en Suecia o Rusia, que llegaría a ser capitán general de Cataluña (Vega, 2010: 273, fig. 127). El uso de estos materiales efímeros como reflejo de la personalidad de Lacy y sus actividades es un juego, como lo es cualquier trampantojo, pero indica el creciente peso del impreso en la circulación de ideas y conocimientos, algo que el propio Lacy conocía bien ya que tuvo entre sus muchas tareas impedir la llegada de las novedades revolucionarias francesas a través de las fronteras del Principado, aunque llegaron, como sabemos, en forma de impresos menores o estampas en numerosos casos. Estos impresos denominados en el ámbito anglosajón "ephemera» cuentan con estudios más limitados en España (Camprubí, 2016; Castillo Gómez, 2015; Ramos Pérez, 2004), de hecho, la búsqueda de una definición no siempre resulta fácil. Clinton, en un trabajo clásico sobre estos materiales, los definía como «documentos que han sido producidos en relación a un acontecimiento determinado o un aspecto de interés puntual y que no pretenden sobrevivir a la actualidad de su mensaje» (Clinton, 1981). Aunque en ocasiones tuvieron la intención de convertirse en algo más que un texto de vida corta, ya que en el caso de algunos pasquines podía quedar como una memoria oral, repetida más allá de la lectura ocasional del cartel o el impreso (Olivari, 2014). Este fue el caso de algunas poesías devotas, como las que se hicieron para difundir la devoción de la Inmaculada en la Sevilla de inicios del siglo xviI, que se repartieron en forma de lluvia de "pétalos" impresos con los poemas y fueron difundidos mediante la recitación de los niños en las calles, reiterando el mensaje textual y oral como medio de promoción devota. El maridaje de oralidad, recitada o pregonada, y difusión impresa mediante carteles, no fue algo ajeno a la comunicación pública de noticias gubernamentales, acontecimientos notables como los festejos de celebración de santidad y otros fenómenos, como la recitación

1. Este artículo forma parte del proyecto «Historia de la publicidad del libro en España: (siglos XV-Xx)» (HAR201346336-P), convocatoria 2013, del Ministerio de Economía y Competitividad. 
de poesías por los ciegos para fomentar la venta (Díaz G. Viana, 2000-2001; Gomís Coloma, 2015). La oralidad textual y la lectura de la tipografía tuvieron en los espacios públicos un encaje singular, propio de un mundo en el que los iletrados necesitaban de la mediación de otros agentes culturales para estar al tanto de las novedades.

En el caso de los carteles que anuncian publicaciones a la venta, nos referiremos más a ausencias que a evidencias materiales de carteles conservados. Lo que podemos aportar son más indicios e hipótesis sobre la presencia del cartel en las calles, a partir de fuentes documentales, referencias en las gacetas, la correspondencia o los propios preliminares de los libros. Las cartas de eruditos suelen incluir referencias a noticias de libros, y a las novedades anunciadas en las gacetas, que fueron una de las fuentes de información más notables del mundo moderno. En la correspondencia de Gregorio Mayans con el barón de Schönberg estos intercambios eran frecuentes. El 12 de agosto de 1738, desde París, el coleccionista le pedía a Mayans que le consiguiera libros, habiendo «juntado a esta Carta una Memoria de algunos libros nuevos exceptos de las Gazetas de Madrid que Vs. se ha servido enviarme» (Mayans, 2002: 106-108). Aunque Mayans advertía de las dificultades para conocer los nuevos títulos, el 28 de abril de 1739 escribía a Schönber para recordarle que «casi todos los libros que salen en España se publican en las Gacetas i después en los mercurios, porque casi todos se venden en Madrid. Pero en no publicándose en Madrid, es dificultoso saber los que salen en otras partes» (Mayans, 2002: 119-121). Las noticias de las novedades podían correr con la posta a través de los intercambios eruditos, pero los muros fueron, sin duda, otro medio de propaganda de las novedades, especialmente en el mundo de la Ilustración.

El ramillete de carteles identificados y localizados es corto, y como suele suceder con los productos tipográficos de las imprentas artesanales, presenta tipologías diversas y responde a necesidades diferentes en cada caso (Castillo Gómez, 2016). En este trabajo seguiremos el análisis propuesto por Infantes que proponía el estudio de la estructura formal y material mediante el análisis bibliográfico y, por otra parte, la reconstrucción de la historia editorial de estos materiales a partir de documentos inéditos. Un análisis que desvelaría la «realidad bifronte de la investigación bibliográfica» (Infantes, 2012: 138). En este artículo nos centraremos al estudio de los usos y las prácticas asociadas a la publicidad del libro y los carteles empleados para difundir las noticias sobre nuevos libros. En gran medida es una mirada centrada en la historia interna, analizando el cartel impreso, y la historia externa, fundamentada en el análisis de los textos históricos coetáneos.

\section{LA PORTADA DEL LIBRO}

En los manuales del arte de la imprenta, que tan brillantemente trabajó Víctor Infantes, encontramos algunas referencias de interés para entender el papel de la portada como medio para mostrar la habilidad del componedor (Sigüenza y Vera, 2017). La portada fue, en más de un sentido, un medio publicitario que tuvo, desde su origen, un creciente peso en la identificación del producto tipográfico del taller de imprenta o en la enunciación editorial de los textos, según como deseemos enfocar el análisis (Infantes, 2006). Tal como recoge Cayuela este enfoque centrado en el contexto de la producción del libro ofrece «enunciados de índole múltiple que hay que reconstruir a través de sus múltiples manifestaciones: un catálogo de editor del xviI, que a través de la selección de unas obras puede lanzar una moda y crear un género, una frase suprimida o añadida por un cajista, un índice elaborado 
por un componedor, una 'mise en page' realizada por un profesional, un grabado elaborado para un frontispicio» (Cayuela, 2015). La identidad del taller y sus materiales se recogían en la portada como una suerte de muestrario convirtiendo a la portada en un mecanismo publicitario de primer orden.

El juego tipográfico con los diferentes cuerpos de letras romanas y cursivas, a una o dos tintas, se convirtió en un elemento sustancial de la presentación de la edición. Una portada que podía vestirse con elementos decorativos que dieran empaque y mayor proyección al texto que promocionaban. A estos elementos se sumaría la marca del impresor, que constituye un elemento de primer orden para conectar con el público y cuya evolución resulta clave para conocer los cambios en la percepción del librero-editor o el impresor. En algunos casos las alegorías que usaron reflejaban un ideal del saber, la fama o las virtudes, convirtiendo al librero en un intermediario cultural imprescindible en la república de las letras. La imagen de Mercurio reconvertido en mensajero de los libreros, dedicado a llevar pesados infolios a los eruditos, fue la imagen elegida en Il giornale de letterati (Parma, 1686) [fig. 1]. En otros casos las adaptaciones iconográficas del mundo clásico podían mostrar a Mercurio (al servicio de los libreros) junto a la representación de la tipografía como Minerva con el casco o una mujer impresora con las balas o el componedor, e incluso en algún emblema llegaron a representarse juntos, tendiendo sus manos como amigos y aliados en la tarea de producir y distribuir los saberes.

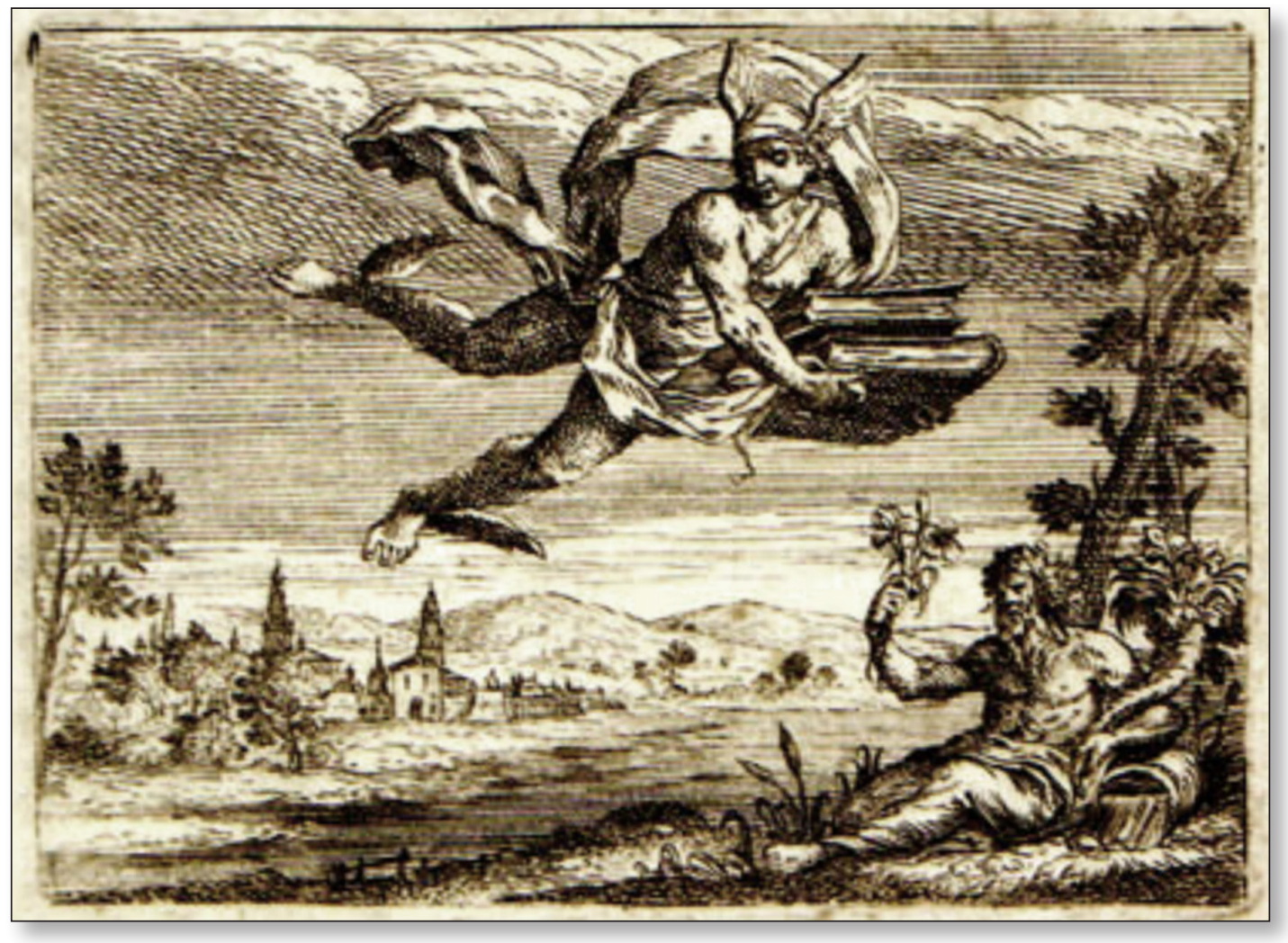

Fig. 1. Mercurio en la portada de Il giornale de letterati (Parma, 1686). 
En ocasiones estas imágenes alegóricas pasarían de las portadas a las cartas de visita o los encabezamientos de facturas o formularios de correspondencia, pero en raras ocasiones estos elementos decorativos refinados pasarían a los catálogos o los carteles, que fueron mayoritariamente tipográficos e informativos en el mundo moderno. En el caso hispánico la tarjeta de visita, que se fue generalizando en el mundo cortesano en el siglo xvIII (Aguilar Piñal, 2000), tardaría en llegar a los circuitos comerciales de la librería, pero en Inglaterra fue un mecanismo publicitario utilizado por perfumeros, zapateros y libreros, con cierta frecuencia, tal como Hubbard propone estas tarjetas comerciales "performed in the ritual of consumption, mediating familial and economic relationships within retailing. As well as communicating economic information, trade cards encoded ideas about taste and status, underscoring the bond between a shopkeeper and his most valued customers» (Hubbard, 2012). La producción de tarjetas de este tipo sería cada vez más común en los muestrarios de las imprentas, e incluso los catálogos de venta de libros llegan a incluir la lista de materiales que pueden imprimirse por encargo, como en el Catálogo de algunas obras que se hallan de venta en la imprenta y despacho de libros de José de Santa María (Murcia, c. 1830-1840) el que se incluyen "tarjetas de varias clases finas» (Catálogo de algunas obras, c. 1830-1840: 19).

Volviendo a la portada como un medio clave para publicitar el libro conviene recalcar que esta misma composición, por su riqueza y complejidad, podía usarse para construir el cartel de promoción de la obra en los espacios públicos. Los primeros carteles impresos anunciando títulos a la venta usaron la tipografía como elemento sustancial. En estos casos se usaban especialmente los cuerpos mayores para destacar en el muro. Un caso ilustrativo, y de los primeros que hemos podido recabar, es el de la publicidad asociada al libro Decisiones et enucleationes criminales, seu Praxis regii criminalis concilii Cathaloniae de Pere d'Amigant i de Ferrer (1645-1707), encargado al impresor barcelonés Rafael Figueró que se publicó en dos volúmenes en los años 1691-1697 [fig. 2]. En 1692 se publicaba el primer volumen que había pagado la Generalitat, fue entonces cuando el impresor recibió un pago complementario de «duas lliuras deu sous per hauer imprimit lo principi de dit llibre per fixar y plantar per los cantons y altres parts de la present ciutat y los restants deu sous per lo treball de plantar dit principi» $»^{2}$. Este principio del libro para fijar por las esquinas debe corresponderse con los datos básicos de la portada tipográfica elaborada por Figueró. El término aviso es el que casa mejor en estos casos, ya que se trata de dar una voz tipográfica destacada a través de recursos textuales. Estos avisos fueron comunes, pero apenas han dejado rastro, excepto en el caso de las instituciones que registraron el pago de estos materiales efímeros. Este sería también el caso de las Memorias de la Real Academia de Buenas impresas en 1756 por Francesc Surià i Ginestar. El libro costó más de 600 libras, y la publicidad en forma de cartel no llegó a las 3 libras e incluía «300 principios para fixar en las esquinas, o sea aviso al público de la obra, comprendido el gasto del mozo que los fixo». De nuevo nos encontramos con estos "principios» de la obra que se fijan en las esquinas por un mozo que se encarga de encolar los muros. El coste de la publicidad y su reparto no llegaba ni al uno por ciento del coste total. ${ }^{3}$

2. Archivo de la Corona de Aragón, Generalitat, Serie General (N), 245, Deliberaciones del Consistorio, 16891692: parte 3, f. 521v-522r, 26 de febrero de 1692 (imagen 726-729 del documento digitalizado disponible en Pares http://pares.mcu.es/).

3. Archivo de la Real Academia de Buenas Letras de Barcelona, 07.01 Carta de 20 de marzo de 1787. Citado por Martínez Martínez, 2016: 48. Agradecemos al autor su autorización para citar este documento localizado en su investigación. 


\section{DECISIONES, E T ENVCLEATIONES CRIMINALES, SEV PRAXIS \\ REGII CRIMINALIS CONCILII, CATHALONIÆ,}

CVRIARVM INFERIORVM , NECNON ALIORVM Tribunalium,Ecclefiafticorum,\&Secularium.

$$
\text { ELVCIDARIVM }
$$

ADMODVM EXOPTATVM, SINGVLATIM , ET ADAMVSSIM recenfens, vfq;ad minimas particulas, proceffus criminalis efformationem, eius incidentia, fententiarum in ritu, \& recto prolationem, \& fubfequentia ad eas, pacis, ac belli tempore.

$$
\text { C O NCI N N A T E }
$$

NOBILI DON PETRO DE AMIGANT, Minoriffenfi, olimin Lyceis Interprote, in Conffftcrïs togato Jplendore emicante, poftea Regio Confliario in Tertia Aula, Fifcique Advocato Regie Curie,nunc iterata buius muneris, rerumque Criminalium dimiffone admi f]a

$\grave{a}$ Concilio fue Maiefatis in Regia eAudientia Civili Principatus Catbalonia, atque in Sancto Fidei Pratorio Confultore.

CVM TRIBVS ELENCHIS, ARGVMENTORVM, QVÆ ENVcleantur, textuum, \& iurium, quę exponuntur, rerum, ac verborum noIVAD DE tabilium, quę in toto hoc primo Volumine continentur.

semination

oter

BAR CINON E:

R.4281

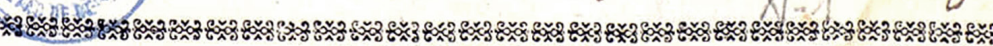

Ex Typographia RAPHAELIS FIGVERó, Typographi

Domus Depurationis, Anno r6gr.

\section{EXCLÒS DE PRÉSTEC}

Fig. 2. Portada de las Decisiones de Amigant (1691). Biblioteca Patrimonial Digital de la Universitat de Barcelona. http://bipadi.ub.edu/ 


\section{LOS CARTELES LIGADOS AL OFICIO}

Los maestros calígrafos tuvieron un notable interés en lograr estudiantes a través de medios publicitarios, que podían elaborar con maestría usando la pluma o haciendo uso de carteles impresos. Este fue el caso de Pierre Dupont que imprimió un cartel anunciando las Séances publiques et gratuites de l'art d'écrire aussi vite que la parole et dans toutes les langues (París?, ca. 1787), dejando en blanco el día, hora y lugar de las sesiones (Petit, 1997: 129). En el caso español conocemos los manuales de estos maestros y su notable papel en la publicación de obras de gran interés para el aprendizaje de las técnicas caligráficas. Aunque apenas hay rastros de los carteles que usaron para atraer a su clientela. Un caso excepcional y de gran valor, que reúne la doble vertiente de docencia en el arte de la pluma y venta de textos del oficio, es el de dos carteles del maestro José García de Moya calificados por Martínez Pereira (2006: 277) como «muestra publicitaria para su escuela». Por lo que sabemos, estos carteles, que difieren en el texto y el diseño caligráfico, pero están destinados a la misma función, son uno de los primeros casos de carteles de venta de materiales impresos conservados de la Corte y uno de los más hermosos por el uso de la caligrafía. Como suele ser habitual no está datado, pero los especialistas citan unas fechas aproximadas en torno a 1661-1682 (Castillo Gómez, 2016). En este caso, García de Moya vendía en «su famosa Escuela de la Escalera de Piedra" muestras de afamados calígrafos, como era el caso de Pedro Díaz Morante y de los hermanos Zabala, que podían ser grabadas o manuscritas (Martínez Pereira, 2006: 277). El caso de los maestros calígrafos resulta de gran interés, ya que además de publicar libros dominaron el arte de preparar muestras manuscritas muy diversas, o producían láminas que, en numerosas ocasiones, ellos mismos podían vender a sus alumnos. El papel docente de estos profesionales les condujo a hacerse con otras muestras, crear cuadernos de ejemplos o vender algunos de los manuales de enseñar a escribir y contar. Al igual que en el universo de las imprentas, el acceso a la cultura escrita y el contar con medios de reproducción mecánicos fue algo común en ambos oficios, compartiendo el interés en conseguir público y ofrecer productos que podían anunciarse mediante carteles.

De hecho, una parte importante de los carteles anunciando acontecimientos puntuales se realizaron a mano, utilizando recursos decorativos limitados, generalmente estos carteles utilizaban letras de mayor tamaño que las habituales. En 1813 Leandro Fernández de Moratín escribía a Francisca Muñoz sobre diversos asuntos, recordando que le escribía cartas «con unas letrazas de cartel de toros, que abultan mucho y dicen poquísimo" (Fernández de Moratín, 1973: 284). El mundillo de los escribanos podía resultar muy variado, con copistas profesionales que podían facilitar trámites copiando documentos, escribiendo cartas o copiando libros, como un Ramón Alvino Muñoz que en México trabajaba como «vendedor de libros a la mano». Este comerciante vendió en 1799 una estampa "con la expresión de la vista del Príncipe Carlos con el General Bonaparte acerca de los preliminares de la Paz» que le fue confiscada. Al preguntarle por el origen de las estampas declaró que las compró a un abridor de láminas denominado Águila, que residía cerca de la Plaza Mayor mexicana. Este artesano había producido las estampas y para corroborarlo afirmó que en el balcón de su vivienda tenía "puesto un rótulo de que allí se abren láminas». ${ }^{4}$ Los rótulos en las calles facilitaron la localización de los puestos de venta, algo que también destaca Mesonero Romanos en las Escenas y tipos matritenses, recordando que se incluía «sobre el cancel un mal

4. Archivo General de la Nación, México, Inquisición, vol. 1.332, exp. 5.

IMAGO, NÚM. 9, 20 I7, I07-I 22 
formado rótulo que en anticuadas letras dirá forzosamente 'LIBRERÍA'». Ahora bien, su opinión, en general no era muy halagüeña, para alguien que había conocido las librerías parisinas (y opinaba con cierto esnobismo) las librerías madrileñas «han permanecido estacionarias, sobreviviendo indiferentes a las revoluciones de la moda y a las convulsiones heroicas del país» (Mesonero Romanos, 2000).

\section{EL ANUNCIO DE LAS NOVEDADES A TRAVÉS DE IMPRESOS}

La publicación de listas de novedades en forma de cartel para fijarse en lugares visibles de los establecimientos, o enviarse por correo a los factores, fue común en algunas imprentas europeas. El uso de estos medios sencillos, impresos en un pliego o en medio pliego, con tiradas cortas y uso efímero, podía realizarse fácilmente en el taller. En ocasiones estas listas de «libros venales» se incluyeron al final de libros publicados, aprovechando algunas páginas en blanco, pero estos medios publicitarios quedaban limitados a los compradores. En otros casos se editaron hojas volantes, que podían repartirse a mano o fijarse en sitios públicos, pero de estas piezas apenas queda rastro. Una de las primeras conservadas fue publicada por William Caxton para promocionar un libro religioso, el Ordinale ad usum Sarum (Westminster, 1477), un impreso de 80 x $146 \mathrm{~mm}$ que está considerado el primer anuncio publicitario de un libro publicado en inglés (Kwakkel, 2014). El impreso finaliza con una cita latina 'Supplico stet cedula' que hace referencia a la súplica de colocar, en muros o puertas, este pequeño cartel. ${ }^{5}$ Es un caso que revela que el tamaño no importa tanto como la función a la que está destinado el anuncio. En los estudios sobre el cartel, este tipo de pequeños impresos destinados a ofrecer información en espacios públicos pasa desapercibido, pero tuvo una importancia decisiva en los primeros siglos de la imprenta. Tal como Sarrazin (2006: 21) indica al ocuparse de los impresos de propaganda de los libros «certains catalogues se limitent à une page, comme le placard d'Alde Manuce, et un très grand nombre, particulièrement les petits catalogues de nouveautés, n'en comptent que quatre». La diversidad de casos revela el empleo de estrategias diferenciadas, incluyendo también la suscripción, como medio de conseguir clientes antes del inicio de la producción del texto en las prensas (Hellinga, 2009).

Un caso de un impreso suelto destinado a publicitar libros es un rarísimo Memorial de las impressions y estampas per a avivar las memorias del Novissims, y camins de la Eternitat (Barcelona?, s.n., s.a.) que fue compuesto en cuarto por una sola cara, con la finalidad de difundir librillos, menudencias y estampas en las zonas rurales. El caso es de gran interés ya que es una de las escasísimas hojas volantes publicitarias que conservamos del mundo moderno. En este caso se trata de unas obrillas destinadas a «los qui vullan provehir dells als Pobles, y Vilas: ab lo comòdo los ne faran los Estampers, y Llibreters de Barcelona, solament se alcanse lo fi, ques la Gloria de Deu, y profit de las Animas». Esta referencia a los que quieran proveer en pueblos y villas es clave ya que indica el papel que pueden jugar los intermediarios locales como mediadores culturales en las áreas del interior de Cataluña. El papel de los presbíteros, capellanes, maestros u otros intermediarios resultaría clave para activar la venta

5. Publicidad del Ordinale ad usum Sarum [Westminster, William Caxton, c. 1476-7]. Repositorio Luna de la Bodleian Library, Bod. Inc. Cat., C-155. <http://bodley30.bodley.ox.ac.uk:8180/luna/servlet/detail/ODLodl 14 14 82954 136822\#> 28-8-17. 
al por menor en estas poblaciones. A la par que los vendedores ambulantes pueden aprovechar la ruta de las misiones para incrementar las ventas de menudencias, ya que el paso de los frailes por las localidades era una oportunidad para mejorar la recaudación. En este impreso, además, se anuncian carteles a la venta, como «los quatre Novissims per pla[n]tar en las parets à 3 [sueldos] la ma», «los matexos Novissims en full de planchas finas fets per lo matex fi, y per plantar en las parets à 6 [sueldos] los quatre» y, también, «los matexos Novissims en quatre quadros pera plantar en las Salas, en las Iglesias, ò altres llochs publichs á 7 [sueldos] lo quadro gran, de quatre fulls majors». Este tipo de estampas tuvieron un notable éxito y en este caso parece probable que el punto de partida fuese el grabado que acompañaba al Desenganys del Apocalypsis de Magí Cases (Socias Batet, 1997; Velandia Onofre, 2013). Esta publicidad de los novísimos se enmarca en la senda que Infantes (1997) trabajó en sus estudios sobre la meditatio mortis. Este impreso es un caso magnífico que ilustra el uso de los tórculos para reforzar el papel de las misiones, multiplicando el mensaje de la predicación con todo un elenco de materiales impresos (Bouza, 2008).

\section{LOS CARTELES EDITORIALES}

El cartel podía fijarse en escaparates, puertas o muros y servir para ofrecer información de títulos editados en un taller de imprenta, las novedades recién publicadas, etc. Del siglo xvIII se conservan pocos ejemplares, en concreto, hay datos fiables de dos carteles madrileños anunciando una nueva obra publicada y tres carteles que ofrecen información de los títulos producidos en la imprenta de Cervera ligada a la nueva universidad instaurada por Felipe V a principios del siglo xviII (Castillo Gómez, 2016; Marina Ruiz, 2016). Los textos literarios ofrecen un panorama interesante que permite detectar los usos posibles del cartel. En El ropavejero literario (Madrid, 1796) se encuentran algunas referencias interesantes a las almonedas de libros, las «librerías de viejo» visitadas por literatos y petimetres de la literatura, sin faltar la referencia a las esquinas «oprimidas más que nunca del peso de los carteles, seguidos unos en otros forman diversas filas, y componen una historia viva de nuestra literatura actual» (Cerdonio, 1796: 23). El autor recalca que se usan los carteles para volver a "anunciar muchas obras atrasadas que no se pudieron vender, o de las que aún quedan muchos exemplares, y se publican también otras de nuevo" (Cerdonio, 1796: 23), esto es algo que podemos detectar en las estrategias de venta, al actualizar mediante el cartel la disponibilidad de un título. En 1794 Moratín le pedía en una de sus cartas a Antonio Melón que «en los paquetes donde está la Comedia hay carteles de ella; haz que se pongan» (Fernández de Moratín, 1973: 105-106). En este caso el dramaturgo intentaba obtener ventaja en la venta de la edición de sus comedias, frente a la competencia que planeaba editarlas. "

En su trabajo pionero Historia de los catálogos de librería españoles (1661-1840) Antonio Rodríguez-Moñino (1966) reprodujo un «cartelón de 1727» que consideró «el más antiguo, español, del que tenemos noticia», un ejemplar que formó parte de su colección. En este caso se trataba de un libro titulado Dirección christiano política, de Victorino de Montemayor, impreso en Madrid por los Herederos de Antonio González Reyes. El cartel, con una orla tipográfica, destacaba en primer lugar que se trataba de un «libro nuevo». Es un aspecto interesante ya que indica el valor dado a la novedad. A continuación se destaca el título, abreviando el que aparece en la portada del libro, pero manteniendo la caja alta en ambos casos con una composición diferente dado que el cartel es apaisado. En este se incluye la in-

IMAGO, NÚM. 9, 2017, 107-122 
formación que aparece en la portada: «Direccion christiano politica, breves reflexiones sobre algunas sentencias de Salomon. Instrucciones para el govierno del hombre sabio", y lo único que se elimina en el cartel es el final de la frase anterior «a quien las ocupaciones disipan el tiempo". La mayor parte del título, tal cual aparece en el libro, se transfiere al cartel. A continuación se incluye en nombre del autor, pero en el cartel no se incluyen ni la dedicatoria ni el pie de imprenta. En este cartel se destaca el punto de venta con el consabido «se hallará en las Gradas de San Felipe el Real, en el Puesto de Pedro Díaz», aspecto que no aparece en la portada. En este caso el cartel anuncia uno de los lugares de venta de libros más conocidos de la Corte, en pleno corazón de Madrid (Sánchez Espinosa, 2011). El cartel incide, de manera rotunda, en destacar que se trata de una novedad editorial, da el título y el autor, y a continuación el lugar donde encontrarlo. La composición es tipográfica, combinando elementos decorativos sencillos (manícula, calderón, adornos vegetales, etc.) y unos cuerpos de letra en caja alta para destacar en el muro. Los impresores y los libreros-editores españoles tuvieron que ingeniárselas para atraer al público en un terreno en el que los grandes mercaderes de libros como Francisco Manuel de Mena jugaron con ventaja, al contar con más medios para hacer llegar las novedades a la clientela o contar con medios publicitarios como las gacetas (Enciso Recio, 1970: 173). El comercio del libro evolucionó durante el siglo xviII y a pesar de las dificultades de principios de la centuria se observan algunos cambios interesantes, con libreros locales que publican pequeños catálogos, como es el caso de Cathalogo de libros de todas facvltades, que se hallaràn en casa de Joseph Ferrer librero de Barcelona (1724), o bien el cartel que hemos descrito. Es muy probable que nuevos estudios puedan dar pistas sobre otros carteles similares, o catálogos editoriales no descritos, ya que el incremento paulatino de la producción y la importación favorecieron una mayor circulación, especialmente en la segunda mitad del siglo (López, 1989). La producción de carteles se fue haciendo más frecuente. El 19 de julio de 1769 el juez de imprentas ordenaba la visita de la imprenta de Francisco Javier García, en la calle de los Capellanes de la Corte, para saber si había impreso, y tenía el privilegio para hacerlo, unas "Cartas o papeles corcenientes a agricultura, frutos y otros particulares, con el cartel que dize aviso al público». La visita al taller no dio sus frutos, ya que en el impresor afirmaba que no se habían impreso ni el libro, ni el cartel. ${ }^{6}$

El uso de carteles, catálogos o prospectos se convirtió en algo más cotidiano, como revela el testimonio de Antonio Valladares en su Seminario erudito. El escritor afirmaba que: «No solo los libreros hacen venir de fuera cualesquiera género de libros, a proporción del consumo; sino que también los libreros extraños movidos del interés, nos inundan con repetidos catálogos de libros venales, convidándonos a que con preferencia se hagan venir de sus tiendas o almacenajes" (Valladares, 1789: 132). Esta riada de efímeros con novedades podía encontrar algunas reticencias por algunos eruditos, pero fue una constante en la correspondencia incluir referencias a estos libreros extranjeros de Lyon o Ginebra que podían hacer llegar remesas de nuevos títulos a los libreros españoles de las grandes ciudades.

Un caso diferente es el de los impresores de Cervera que publicaron carteles para publicitar la exclusividad de venta y edición de determinadas obras cedidas por la Corona para financiar las actividades de la nueva universidad. En el contrato de arriendo del privilegio firmado por el impresor Ibarra, el 19 de septiembre de 1754, se indicaba que debía mantener abastecidos los estanquillos en las principales ciudades (Burgos Rincón, 1997). La publicación de carteles permitía dar a conocer los títulos disponibles y sus precios, con la finalidad de garantizar una venta a precio fijo en el Principado de Cataluña. Cualquier mo-

6. Archivo Histórico Nacional, Madrid Consejos, 50687. 
dificación en los precios hacía necesaria su renovación para volver a fijar en los estancos los precios a la vista del público. En la documentación conservada de esta imprenta cervariense en el Archivo Histórico de la Universidad de Barcelona se conservan ejemplares de cuatro carteles impresos, que fueron transcritos por Rubio y Borrás (1915-1916) y recientemente han sido analizados por Ruiz Fargas (2016). El título refuerza la idea de punto de venta, indicando en su inicio el Precio a que se venden los libros de Privativa de la Real Universidad de Cervera [Cervera, s.a.]. Este primer cartel conocido Ruiz Fargas (2016) lo adscribe a la primera etapa de Manuel Ibarra en Cervera, documentada desde junio de 1735 hasta agosto de 1749. Otros dos carteles, en poco tiempo, volvieron a destacar el Precio a que se venden los libros de Privativa con la lista de la resolución del 1 de julio de 1756 y la del 25 de junio de 1757. El cuarto cartel es posterior, probablemente de inicios del siglo xIx, dado que se obvia cualquier referencia a la Privativa, con el título de Nota de los libros que se hallan en la oficina de la imprenta de la Universidad de Cervera, y del precio á que se venden en papel [Cervera, s.a.]. Esta nota o aviso reúne obras comunes en numerosos centros de enseñanza, que fue uno de los aspectos más discutidos por los libreros al considerar que la privativa restaba posibilidades de negocio a sus oficinas.

\section{INCURSIÓN ROMÁNTICA}

En el mundo hispánico es difícil seguir el rastro a la representación en imágenes de los carteles fijados en las paredes de las ciudades, pero algunas representaciones francesas o inglesas de los que las fijan, en el acto de ocupar el espacio público, revelan el creciente interés por representar estos oficios menores con la escalera, la cola y los avisos para fijar en los muros ocupándose de anunciar novedades editoriales (Myers, Harris, 1990). En algunas representaciones se incluye a los observadores, que rumian la novedad anunciada. Esta imagen del consumo de novedades se acaba sumando a la lectura como acto de ocio de la sociedad burguesa que forma parte de la cosmovisión decimonónica del libro. El mercado editorial peninsular era frágil y se encontraba en proceso de evolución a fórmulas empresariales. En todo caso hubo iniciativas de notable interés, como la de Dionisio Hidalgo que intentaba con su compañía Unión Literaria sacar «a la librería española del letargo en que yace sumergida" (cit. Martínez Millán, 2002: 19), lo que incluía mejorar las herramientas de comunicación del oficio (revistas profesionales, mejores catálogos editoriales, diversificar los medios publicitarios, etc.).

En algunos casos el cartel, sencillamente, se representa como parte de la decoración mural de las calles. De nuevo, es necesario recurrir a fuentes del siglo xix para conseguir localizar estos escurridizos carteles librescos. El anuncio de un libro aparece en imágenes del mundo urbano que, en algunos casos, incluyen muros decorados con carteles que publicitan novedades editoriales. Este sería el caso de una de las vistas ópticas realizadas por Onofre Alsamora Peracaula (c. 1847-1850) que representaban escenas urbanas de Barcelona (Cuenca Córcoles, 2015: 28-30) [fig. 3].

En una de ellas se observan las torres antiguas en la Plaza Nueva de Barcelona que representan unos soportales (hoy en día desaparecidos) en los que aparecen varios carteles impresos [fig. 4]. ${ }^{7}$ Uno de ellos de color amarillo anuncia una actividad del Liceu barcelonés,

7. Archivo Histórico de la Ciudad de Barcelona. Gráficos, 12403.

IMAGO, NÚM. 9, 2017, 107-122 
otro ya roto y casi desmenuzado de papel blanco anuncia un Diccionario firmado por D.P.L. En este caso podría tratarse del Diccionario de la lengua castellana con las correspondencias catalana y latina de Pere Labèrnia i Esteller (1802-1860) que tuvo un notable éxito editorial. Este último cartel se superpone sobre otro (azul) que anuncia un tratado del que poco más sabemos.

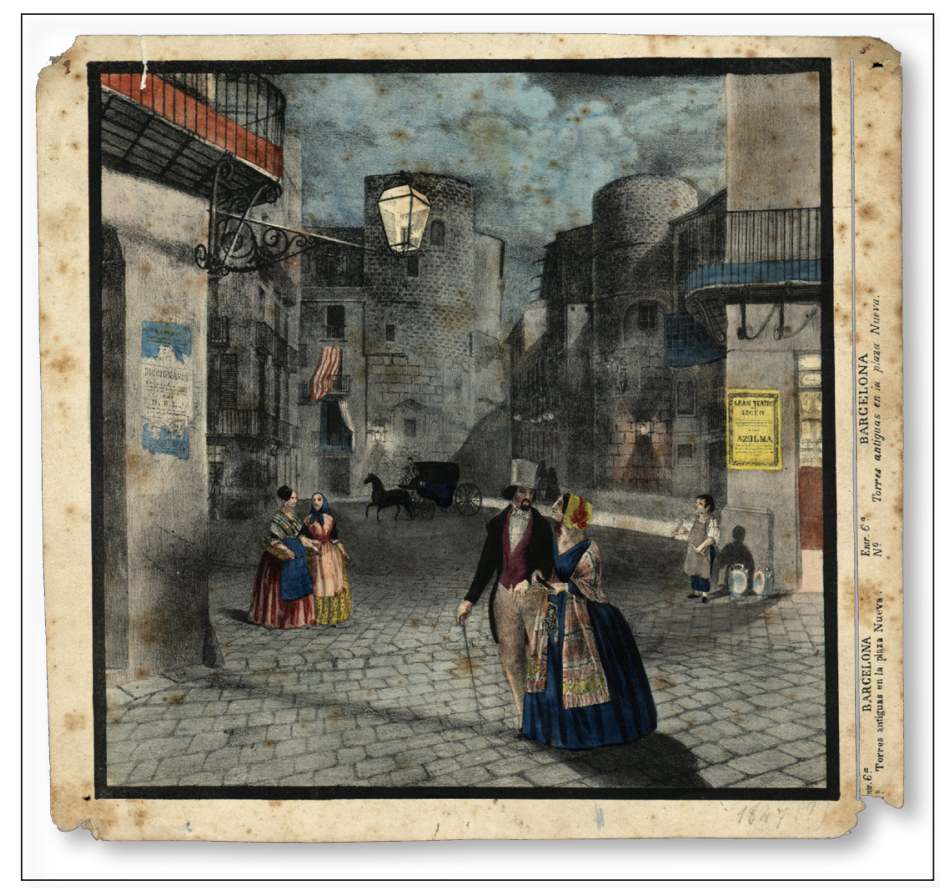

Fig. 3. Las torres antiguas en la Plaza Nueva de Barcelona, c. 1847-1850.

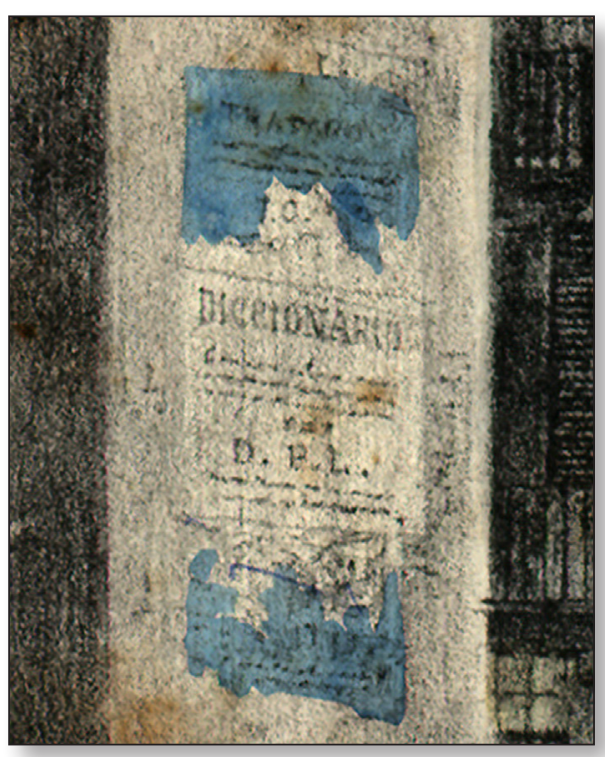

Fig. 4. Detalle de los carteles que anuncian libros, c. 1847-1850. 
En otros casos estos carteles o cartulinas publicitarias, al igual que los almanaques, se fijaban en el interior de los establecimientos para anunciar novedades, en muchos casos obras de éxito que solían tener salida comercial y muy especialmente los almanaques [fig. 5]. En la edición de 1851 de las Escenas y tipos matritenses se representa una librería tradicional, con un mostrador y el regente del negocio conversando con un cliente que "vive tranquilamente encuadernado en su mostrador de pino y sus anaqueles de becerro» (Mesoneros Romanos, 2000: Costumbres literarias, III. La librería). Al fondo se observan varios avisos de libros con el Catecismo de Ripalda, un Arte de cocina y otros, sin que sirva más que para completar la escena costumbrista. La sencillez de estos carteles y sus usos publicitarios hicieron que se renovasen con relativa facilidad y, en la mayoría de los casos, simplemente hayan desaparecido.

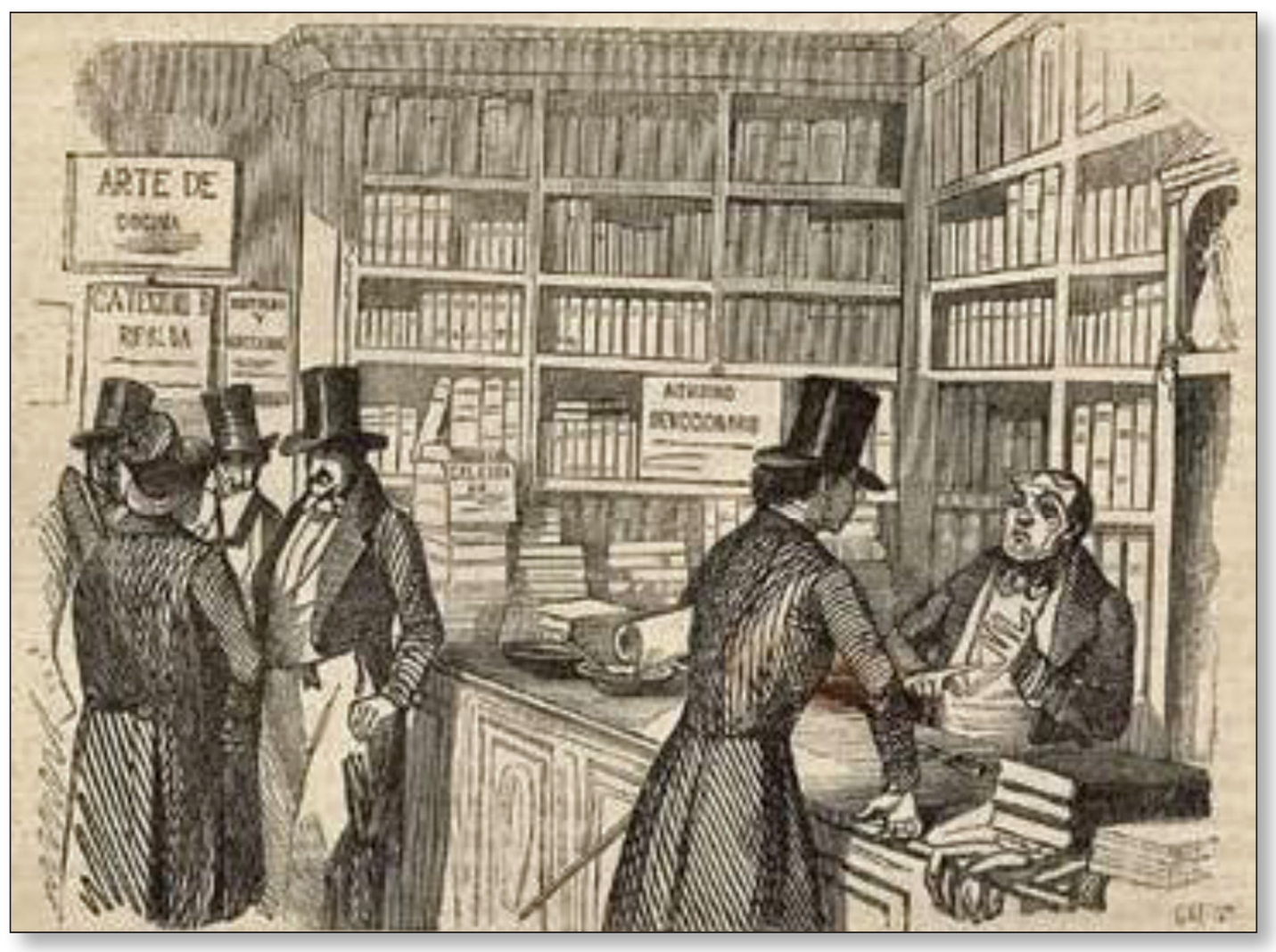

Fig. 5. Carteles en el interior de una librería a mediados del siglo xix. Mesonero Romanos, Escenas y tipos matritenses (1851).

\section{CONCLUSIONES}

En resumen, el mundo del cartel que anuncia libros a la venta ofrece una panorámica (por ahora) incompleta pero rica, con un muestrario de carteles preservados escaso, pero unos testimonios literarios y documentados de sus usos que invitan a la reflexión sobre el uso

IMAGO, NÚM. 9, 2017, 107-122 
de espacios públicos para informar de las novedades editoriales. Estos carteles en los muros amplifican, de manera notable, el uso de las gacetas o los prospectos, logrando un universo de comunicación más diversificado para los avisos públicos de los nuevos libros editados en el mundo moderno. Los testimonios de carteles indican que, al menos, desde finales del siglo xvII, fue un fenómeno del que hay testimonios. Aunque el primer cartel del que hay noticias fiables (y ha sido reproducido) es de 1727. Estos medios efímeros, destinados a ser fijados en las paredes "en los lugares acostumbrados», como se decía en uno de los documentos citados, indican que hay usos sociales comunes para difundir en los lugares más concurridos por el público estos papeles de pared destinados a ofrecer autores y títulos a la curiosidad de los paseantes.

\section{BIBLIOGRAFÍA}

Aguilar Piñal, F. [2000]. "Otra innovación del siglo xviII: las tarjetas de visita», Bulletin Hispanique, 104, 1, 23-39.

BouzA, F. [2008]. «De golosina y otras industrias jesuíticas: de la prédica a la imprenta», en P. Chinchilla y A. Romano (ed.), Escrituras de la modernidad. Los jesuitas entre cultura retórica y cultura científica, México, Universidad Iberoamericana; Paris, Ecole des Hautes Etudes en Sciences Sociales, 306-325.

Burgos Rincón, J. [1997]. «Privilegios de imprenta y crisis gremial: la imprenta y la librería barcelonesa ante el privilegio de impresión de los libros de enseñanza de la Universidad de Cervera», Estudis històrics $i$ documents dels arxius de protocol, 15, 257-298.

CAmprubí, X. [2016]. «Butlletes, fulls solts i altres menuderies: la contribució de la impremta al funcionament de la societat catalana moderna», Manuscrits, 34, 113-144.

Cases, M. [1974]. Desenganys del Apocalypsis, Barcelona, Curial.

Castillo Gómez, A. [2015]. "Efímeros y menudencias. Otras lecturas en tiempos de Carlos I», en Bibliotecas y librerías en la España de Carlos V, Barcelona, Calambur, 123-152.

Castillo Gómez, A. [2016]. "'Véndese en la tienda de...' Apuntes sobre la publicidad del libro en la España moderna», en P. Rueda Ramírez, Ll. Agustí (eds.), La publicidad del libro en el mundo hispánico (siglos XVII-XX): los catálogos de venta de libreros y editores, Madrid, Calambur, 87-113.

CATÁLOGO DE ALGUNAS OBRAS [c. 1830-1840]. Catálogo de algunas obras que se hallan de venta en la imprenta y despacho de libros de José de Santa María, [Murcia, Imp. de José de Santa María].

Cayuela, A. [2015]. "'Esta pobre habilidad que Dios me dio': Autores, impresores, editores en el entuerto de la publicación (siglos XVI-XVII)", Tiempos modernos, 8, 31. < http://www. tiemposmodernos.org/tm3/index.php/tm/article/view/555/583> 31-8-17.

CeRDonio, D. [1796]. El ropavejero literario, en las ferias de Madrid: obra tan útil como las demás y tan inocente como pocas, Madrid, Impr. de Villalpando.

Clinton, A. [1981]. Printed Ephemera. Collection, organisation and access, London, Clive Bingley.

Cuenca Córcoles, C. [2015]. Onofre Alsamora (c.1810-1880). La il.lusió de l'òptica: del retrat urbà a les primeres vistes òptiques de Barcelona del segle XIX. Trabajo final del grado de Humanidades. Barcelona, Universitat Pompeu Fabra. <http://hdl.handle.net/10230/25239> 28-8-17.

Enciso Recio, L. M. [1970]. «La imprenta Real a fines del siglo xvIII (1782-1795)», Revista de la Universidad de Madrid, 19, 73, 169-194. 
Fernández de Moratín, L. [1973]. Epistolario, R. Andioc (ed.), Madrid, Castalia.

Finestres i de Monsalvo, J. [1933-1969]. Epistolari, Barcelona, Biblioteca Balmes.

Gomis Coloma, J. [2015]. Menudencias de imprenta. Producción y circulación de la literatura popular (Valencia, siglo XVIII), València, Institució Alfons el Magnànim.

Hellinga, L. [2009]. "Sale advertisements for books printed in the fifteenth century», en R. Myers, M. Harris y G. Mandelbrote (eds.), Books for sale: the advertising and promotion of print since the fifteenth century, New Castle, Oak Knoll Press; London, British Library, 1-25.

Hubbard, Ph. [2012]. "Trade Cards in 18th-Century Consumer Culture: Movement, Circulation, and Exchange in Commercial and Collecting Spaces», Material Culture Review, 74-75, 30-46.

INFANTES, V. [1997]. Las danzas de la muerte: génesis y desarrollo de un género medieval: siglos XIIIXVII, Salamanca, Ediciones Universidad de Salamanca.

InfANTES, V. [2012]. «La 'muestra de impresión': un testimonio inédito de la estrategia editorial del Siglo de Oro», en A. Cayuela (coord.), Edición y literatura en España (Siglos XVI y XVII), Zaragoza, Prensas Universitarias de Zaragoza.

KWAKKel, E. [2014]. «Medieval spam: The oldest advertisements for books». Blog Medieval Books. <https://medievalbooks.nl/2014/12/05/medieval-spam-the-oldest-advertisements-for-books/> 29-8-17.

López, F. [1989]. "La edición española bajo el reinado de Carlos III», en Actas del Congreso Internacional sobre Carlos III y la Ilustración, Madrid, Ministerio de Cultura, III, 279-303.

Mandelbrote, G. [2000]. "La nouvelle édition de Graham Pollard et Albert Ehrman, The distribution of books by catalogue from the invention of printing to $A D 1800$ ", en A. CHARON y É. PARINeT (eds.), Les ventes de livres et leur catalogues, XVII $-X X^{e}$ siècle, Paris, 49-76.

Martínez Martínez, O. [2016]. L'impressor Francesc Surià i Burgada (1749-1805). Trabajo Final del Máster en Bibliotecas y Colecciones Patrimoniales. Inédito.

Martínez Millán, J. A. [2002]. «El mercado editorial y los autores. El editor Delgado y los contratos de edición», en M.-L. Ortega (ed.), Escribir en España entre 1840 y 1876, Madrid, Visor Libros, 13-33.

Martínez Pereira, A. [2006]. Manuales de escritura de los Siglos de Oro: repertorio crítico y analítico de obras manuscritas e impresas, Mérida, Editora Regional de Extremadura.

Mayans, G. [2002]. Epistolario: Mayans y el Barón de Schönberg, transcripción y estudio preliminar S. Aleixos, A. Mestre, Valencia, Departamento de Historia Moderna, Universitat de València.

Mesonero Romanos, R. [2000]. Escenas y tipos matritenses, Alicante, Biblioteca Virtual Miguel de Cervantes. Edición digital a partir de la de Madrid, Imprenta y litografía de Gaspar Roig, 1851. <http://www.cervantesvirtual.com/bib_autor/mesonero/> 24-8-17.

Olivari, M. [2014]. Avisos, pasquines y rumores: los comienzos de la opinión pública en la España del siglo XVII, Madrid, Cátedra.

Osuna, I. y Infantes, V. [2011]. «Paredes de versos dibujadas. Fábrica y materia del cartel poético barroco (1650-1700)», Bulletin Hispanique, 113, 1, 163-238.

Petit, N. [1997]. L'éphémère, l'occasionnel et le non livre à la bibliothèque Sainte-Geneviève (XveXVIII siècles), Paris, Klincksieck.

Ramos PéRez, R. [2004]. «La publicidad relacionada con el libro en la Colección de Ephemera de la Biblioteca Nacional", Encuadernación de Arte: revista de la Asociación para el Fomento de la Encuadernación, 23, 56-65. 
Ruiz Fargas, M. [2016]. «El privilegio de privativa de libros de común enseñanza de la Universidad de Cervera en tiempos de Manuel Ibarra (1735-1749, 1754-1757)», en P. Rueda Ramírez, Ll. Agustí (eds.), La publicidad del libro en el mundo hispánico (siglos XVII-XX): los catálogos de venta de libreros y editores, Madrid, Calambur.

Sánchez Espinosa, G. [2011]. «Los puestos de libros de las gradas de San Felipe de Madrid en el siglo xvIII", Goya. Revista de arte, 335, 142-155.

Sarrazin, V. [2006]. «Introduction», en C. Lesage, È. Netchine y V. Sarrazin (comp.), Catalogues de libraires: 1473-1810, Paris, Bibliothèque nationale de France.

SigüEnZa y Vera, J. J. [2017]. Mecanismo del arte de la imprenta para facilidad de los operarios que la exerzan, Madrid, Turpin Editores.

Socias Batet, I. [1993]. «El contracte dels quatre gravats dels Novíssims, entre l'impressor i gravador Joan Jolis Santjaume i Magí Cases, doctor en teologia", Pedralbes: revista d'història moderna, 13, 2, 449-462. <http://www.raco.cat/index.php/Pedralbes/article/ view/103409/152176> 29-8-17.

Valladares, A. [1789]. Seminario erudito, Madrid.

VegA, J. [2010]. Ciencia, arte e ilusión en la España ilustrada, Madrid, Polifemo.

Velandia Onofre, D. [2013]. "No solo palabras. El uso de imágenes en la predicación postridentina en Cataluña», en S. CANalda, C. Fontcuberta (eds.), Imatge, devoció i identitat a l'època moderna: segles XVI-XVIII, Barcelona, Universitat de Barcelona; Bellaterra, Universitat Autònoma de Barcelona, 169-183. 